\title{
Longitudinal Expression of Testicular TAS1R3 from Prepuberty to Sexual Maturity in Congjiang Xiang Pigs
}

\author{
Ting Gong ${ }^{1,2,3}$, Weiyong Wang ${ }^{1,2,3}$, Houqiang Xu ${ }^{1,2,3, *}$, Yi Yang ${ }^{1,2,3}$, Xiang Chen ${ }^{1,2,3}$, Lijie Meng ${ }^{1,2,3}$, \\ Yongjian $\mathrm{Xu}^{1,2,3}$, Ziqing $\mathrm{Li}^{3}$, Sufang $\mathrm{Wan}^{3}$ and Qi Mu ${ }^{3}$ \\ 1 Key Laboratory of Animal Genetics, Breeding and Reproduction in The Plateau Mountainous Region, \\ Ministry of Education, Guizhou University, Guiyang 550025, China; tgong@gzu.edu.cn (T.G.); \\ wangxiaochui369@163.com (W.W.); yiyangnutrition@foxmail.com (Y.Y.); as.xchen2@gzu.edu.cn (X.C.); \\ mlj18208544454@163.com (L.M.); xuyongjian0503@163.com (Y.X.) \\ 2 Key Laboratory of Animal Genetics, Breeding and Reproduction, Guiyang 550025, China \\ 3 College of Animal Science, Guizhou University, Guiyang 550025, China; ZQli98@163.com (Z.L.); \\ w18385462413@163.com (S.W.); Muqi0524@163.com (Q.M.) \\ * Correspondence: houqiangxu2020@163.com; Tel.: +86-0851-88298005
}

check for updates

Citation: Gong, T.; Wang, W.; Xu, H.; Yang, Y.; Chen, X.; Meng, L.; Xu, Y.; Li, Z.; Wan, S.; Mu, Q. Longitudinal Expression of Testicular TAS1R3 from Prepuberty to Sexual Maturity in Congjiang Xiang Pigs. Animals 2021, 11, 437. https://doi.org/10.3390/ ani11020437

Academic Editor: Olli A.T. Peltoniemi Received: 2 December 2020

Accepted: 29 January 2021

Published: 8 February 2021

Publisher's Note: MDPI stays neutral with regard to jurisdictional claims in published maps and institutional affiliations.

Copyright: (c) 2021 by the authors Licensee MDPI, Basel, Switzerland. This article is an open access article distributed under the terms and conditions of the Creative Commons Attribution (CC BY) license (https:// creativecommons.org/licenses/by/ $4.0 /)$.
Simple Summary: Taste receptor type 1 subunit 3 (T1R3), a sweet/umami taste receptor, is widely expressed from the tongue to the testis, and testis expression is associated with male sterility. In Congjiang Xiang pigs, T1R3 is expressed in elongating/elongated spermatids and Leydig cells in a stage-dependent manner during postnatal development and the spermatogenic cycle. T1R3 may contribute to regulation of spermatid differentiation and Leydig cell function, and may therefore help limit the incidence of various male reproductive pathologies.

Abstract: Testicular expression of taste receptor type 1 subunit 3 (T1R3), a sweet/umami taste receptor, has been implicated in spermatogenesis and steroidogenesis in mice. We explored the role of testicular T1R3 in porcine postnatal development using the Congjiang Xiang pig, a rare Chinese miniature pig breed. Based on testicular weights, morphology, and testosterone levels, four key developmental stages were identified in the pig at postnatal days 15-180 (prepuberty: 30 day; early puberty: 60 day; late puberty: 90 day; sexual maturity: 120 day). During development, testicular T1R3 exhibited stage-dependent and cell-specific expression patterns. In particular, T1R3 levels increased significantly from prepuberty to puberty $(p<0.05)$, and expression remained high until sexual maturity $(p<0.05)$, similar to results for phospholipase C $\beta 2$ (PLC $\beta 2)$. The strong expressions of T1R3/PLC $\beta 2$ were observed at the cytoplasm of elongating/elongated spermatids and Leydig cells. In the eight-stage cycle of the seminiferous epithelium in pigs, T1R3/PLC $\beta 2$ levels were higher in the spermatogenic epithelium at stages II-VI than at the other stages, and the strong expressions were detected in elongating/elongated spermatids and residual bodies. The message RNA (mRNA) levels of taste receptor type 1 subunit 1 (T1R1) in the testis showed a similar trend to levels of T1R3. These data indicate a possible role of T1R3 in the regulation of spermatid differentiation and Leydig cell function.

Keywords: T1R3; testis; Congjiang Xiang pig; developmental biology

\section{Introduction}

Taste sensations enable animals to evaluate which prospective foods are nutritious or toxic. Members of the taste receptor family 1 (T1Rs), encoded by TAS1R genes, T1Rs are largely responsible for sensing sweet and umami tastes in the taste buds. Taste receptor family 1 subunit 1 (T1R1)/taste receptor family 1 subunit 3 (T1R3) heterodimers form an umami taste receptor, and the taste receptor family 1 subunit 2 (T1R2)/T1R3 heterodimers recognize sweet tastes [1]. In taste cells, a heterotrimeric GTP-binding protein (gustducin)mediated signaling cascade can be activated when T1Rs sense umami or sweet stimuli. A 
GTP-protein consisting of 2 subunits, $\alpha$-gustducin (G $\alpha$ gust) and $\beta \gamma$-gustducin (G $\beta \gamma$ gust), activates phospholipase $\mathrm{C} \beta 2$ (PLC $\beta 2$ ) to increase intracellular $\mathrm{Ca}^{2+}$ levels. Gagust is expected to activate phosphodiesterase (PDE), resulting in decreased intracellular cyclic adenosine monophosphate (cAMP) levels after ligand binding [1].

Although T1R3 was first detected in the tongue and contributes to the perception of acceptable foods, an increasing number of studies have reported the expression of T1R3 and its related signaling transduction cascade in non-taste tissues, including the digestive system, respiratory system, urinary bladder, pancreas, liver, brain, and testis [2].

There is evidence that testicular T1R3 may function in male sterility. For example, T1R3 is highly expressed in swine testicular tissues, especially in spermatogenic cells [3]. In mice, T1R3 and its related molecules, T1R1, $G_{\alpha g u s t}$, and taste receptor family 2 subunit 5 (T2R5), were primarily detected in developing haploid spermatids [4,5]. These molecules are localized in testicular Leydig cells, epididymal spermatozoa and semen [4-6]. Interestingly, many initial components of sweet/umami taste signaling cascades, such as PLC $\beta 2$, G protein $\gamma 13$ subunit (G $\gamma 13$ ), and transient receptor potential channel M5 (TRPM5), are also expressed in testicular Leydig cells and late spermatogenic cells $[7,8]$. In addition, T1R1/T1R3 expressed in the flagella and acrosomal cap of sperm in mice regulates basal $\mathrm{Ca}^{2+}$ and cAMP levels during sperm development, maturation, and fertilization [6,9]. Genetic absence of both Tas1r3 and G protein subunit alpha transducin 3 (Gnat3) leads to specific sterility in male mice [10]. Clofibrate-mediated inhibition of humanized TAS1R3 in Tas1r3- / - , Gnat3 - / - double-null mice leads to inducible male sterility [10]. In our previous studies, we have shown that mouse testicular T1R3 and its associated heterotrimeric Gogust are expressed in the testis in a stage-dependent manner during development, and with a cell-specific pattern during the spermatogenic cycle [11].

Owing to the role of T1R3/Gagust in spermatogenesis and steroidogenesis in the mouse testis [9,11,12], we hypothesized that TAS1R3 contributes to testis development in the Congjiang Xiang pig, a rare Chinese indigenous breed characterized by a small body size, with an adult body weight of approximately $40 \mathrm{~kg}$ (while other minipigs are about $60 \mathrm{~kg}$ ) [13]. They reach sexual maturity at the age of around 3-4 months and have high disease resistance, favorable meat quality and strong adaptability [13-15]. Since Congjiang Xiang pigs share many anatomical and physiological features with humans (including the organ weights and blood physiological and biochemical indicators) [13] and their relatively small size makes them easier to handle and more manageable than other varieties of pigs [13], they are a potential model for biomedical research and xenotransplantation [16]. Studies of Congiiang Xiang pigs have focused on the determination of their characteristics as germplasm resources [14,15], and little is known about the gene regulatory mechanisms underlying the highly complex cellular remodeling associated with spermatogenesis and male hormone secretion. In the present study, we examined the expression profiles of T1R3 in the testes of Congiiang Xiang pigs; our results provide insight into the process of testis development and the onset of the first spermatogenic wave in the breed.

\section{Material and Methods}

\subsection{Animals and Ethics Statement}

All animal procedures were approved by the Institutional Animal Care and Use Committee of Guizhou Medical University (No. 1801227, Guiyang, China) and the Guizhou University Experimental Animal Ethics (No. EAE-GZU-2020-P001, Guiyang, China). All experimental procedures were conducted in accordance with the Regulations for the Administration of Affairs Concerning Experimental Animals approved by the State Council of the People's Republic of China. Male Congjiang Xiang pigs were obtained from the Guizhou Lushengyuan Animal Husbandry Technology Development Co., Ltd. (Guiyang, China) at postnatal day 15, 30, 60, 90, 120, and 180. Each time-point had six individual animals. Newborn piglets were housed with their mother sows before weaning and each lactating sow was housed in an individual pen. Eighteen piglets were castrated at 15, 30, and 60 day, respectively. The uncastrated piglets $(n=18)$ were weaned at 60 day and then 
also housed in individual pens with ad libitum access to water and a well-ventilated room maintained at $20-26^{\circ} \mathrm{C}$ and $50-70 \%$ humidity until sampling. They were fed 3 meals per day at volumes to ensure free feed intake.

\subsection{Experimental Design}

Based on the testis stereology and morphology, as well as the plasma testosterone concentrations of Congjiang Xiang pigs at six time-points during postnatal development (i.e., 15 day, 30 day, 60 day, 90 day, 120 day, and 180 day), key stages (including prepuberty: 15 day, 30 day; early puberty: 60 day; late puberty: 90 day; sexual maturity: 120 day, 180 day) related to testis development were identified. The expression levels of T1R3 and the associated signaling pathway components T1R1 and PLC $\beta 2$ were evaluated at the above-mentioned stages of testis development by Western blotting (WB), immunohistochemical (IHC) analysis and quantitative real-time PCR (q-PCR). In addition, the expression patterns of T1R3 and PLC $\beta 2$ during the spermatogenic cycle of Congjiang Xiang pigs at sexual maturity were determined by IHC.

\subsection{Tissue Preparation}

Prior to sampling, the body weight of each animal (age 15-180 day) was recorded. Blood (from the jugular vein, $5 \mathrm{~mL}$ ) and testes were collected after animals were anesthetized by $0.04 \mathrm{mg} / \mathrm{kg}$ atropine sulfate salt monohydrate (A0257; Sigma-Aldrich. St. Louis, MO, USA) via intramuscular injection in the hip. Surgical castration involved making an incision over the disinfected scrotum via the vaginal tunic and removing the testis by a combination of traction and twisting. The wound was treated with antibiotics and an antiseptic spray and was left open to heal. All surgical procedures were performed by a veterinarian. The plasma was separated from blood by centrifugation at $4000 \mathrm{rpm}$ for $10 \mathrm{~min}$ and stored at $-80{ }^{\circ} \mathrm{C}$ for hormone evaluation. After orchiectomy, the two sides of the testes in each boar were weighed and harvested immediately. Testis samples were taken from the central region of each of the left testes and washed three times with phosphate-buffered saline (PBS). Next, each sample was divided into two parts, and immediately frozen in liquid nitrogen and stored at $-80^{\circ} \mathrm{C}$ for RNA preparation and WB, respectively. Each of the right testes were removed and cut into 2 portions of $1 \mathrm{~cm}^{3}(10 \mathrm{~nm} \times 10 \mathrm{~nm} \times 10 \mathrm{~nm})$ in volume. According to our previous studies [17], one portion was fixed in modified Davidson's fluid $(\mathrm{mDF})$ for hematoxylin and eosin (H\&E) staining and the other portion was fixed in $4 \%$ paraformaldehyde (PFA) for IHC analysis. Additionally, 60 day mouse testis sections were donated by Prof. Fangxiong Shi's group (Nanjing Agricultural University, Nanjing, China).

\subsection{Testosterone Assay}

Plasma hormone concentrations of testosterone were determined by an enzymelinked immunosorbent assay (ELISA) using a commercial Porcine Testosterone (T) Elisa Kit (201902; Nanjing Jiancheng Bioengineering Institute, Nanjing, China). Detection was performed at $450 \mathrm{~nm}$ using a Varioskan LUX Multimode Microplate Reader (Thermo Fisher Scientific, Waltham, MA, USA). The lower limit of detection of the kit was $0.6 \mathrm{nmol} / \mathrm{L}$, and the intra- and interassay coefficients of variation were $<10 \%$ and $12 \%$, respectively. Assays were performed in triplicate.

\subsection{Quantitative Real-Time PCR ( $q-P C R)$}

Three animal samples from each time-point passed quality control, and were selected for q-PCR assay.

Total RNA was extracted from porcine testes at prepuberty (30 day), early puberty (60 day), late puberty (90 day), and sexual maturity (120 day) using TRIzol Reagent (15596026; Thermo Fisher Scientific, Inc., Waltham, MA, USA) according to the manufacturer's protocol. Total RNA was dissolved in $30 \mu \mathrm{L}$ RNase-free deionized water and stored at $-80{ }^{\circ} \mathrm{C}$. The quality of RNA was assessed by a NanoDrop 2000 spectrophotometer (Thermo Fisher Scientific, Wilmington, DE, USA), and the RNA samples had A260/280 ratios of approximately 
1.98-2.14, A260/230 ratios ranged between 2.01-2.20, and high integrity (Figure S1 and Table S1), which is acceptable for downstream applications [18]. For each available sample (Table S1), cDNA was synthesized using the Revert Aid First Strand cDNA Synthesis Kit (K1622; Thermo Fisher Scientific, Inc., Waltham, MA, USA) and used as a template for PCR. q-PCR was performed on the CFX96 real-time PCR system (Bio-Rad, Hercules, CA, USA) using Power UP SYBR GREEN Master Mix (A25742, Thermo Fisher Scientific, Inc., Waltham, MA, USA).

The PCR amplification was performed in a total volume of $10 \mu \mathrm{L}$ containing $5 \mu \mathrm{L}$ of $2 \times$ Es Taq Master Mix, $2 \mu \mathrm{L}$ of RNase-free $\mathrm{dH}_{2} \mathrm{O}, 1 \mu \mathrm{L}$ of cDNA, and $1 \mu \mathrm{L}$ each of forward and reverse primers $(10 \mathrm{pmol} / \mu \mathrm{L})$. Each PCR cycle included a denaturation step at $95^{\circ} \mathrm{C}$ for $3 \mathrm{~min}$, followed by 40 cycles of $95^{\circ} \mathrm{C}$ for $15 \mathrm{~s}, 58.4-60^{\circ} \mathrm{C}$ for $15 \mathrm{~s}$, and extension at $72^{\circ} \mathrm{C}$ for $1 \mathrm{~min}$, and a dissociation step consisting of $95^{\circ} \mathrm{C}$ for $15 \mathrm{~s}, 60^{\circ} \mathrm{C}$ for $1 \mathrm{~min}$, and $95^{\circ} \mathrm{C}$ for $15 \mathrm{~s}$. Gene expression levels of target genes (TAS1R1, TAS1R3, and PLCB2) were normalized against levels of the selected housekeeping gene ATCB [19] (Figure S2 and Table S2) and expressed as $2^{-\Delta \Delta C T}$ [20] using samples on day 30 for calibration. The standard curve for each primer pair was run in one plate for q-PCR. The primers for q-PCR are listed in Table 1. The amplification efficiency of all primer pairs ranged from $90.1-102.0 \%$, and the $R^{2}$ values were greater than 0.99 (Figure S3).

Table 1. The primers for q-PCR.

\begin{tabular}{|c|c|c|c|c|c|}
\hline Gene Name & $\begin{array}{l}\text { NCBI Reference } \\
\text { Sequence }\end{array}$ & $\begin{array}{l}\text { Oligonucleotide Primers } \\
\qquad\left(5^{\prime}-3^{\prime}\right)\end{array}$ & $\begin{array}{l}\text { Expected Products } \\
\text { Size (bp) }\end{array}$ & $\begin{array}{c}\text { Melting Temperature } \\
\left(\mathrm{Tm},{ }^{\circ} \mathrm{C}\right)\end{array}$ & $\begin{array}{l}\text { Amplification } \\
\text { Efficiency (\%) }\end{array}$ \\
\hline TAS1R3 & NM_031872.2 & $\begin{array}{c}\text { Forward: TCATCAC- } \\
\text { CTGGGTTTCCTT } \\
\text { Reverse: GGGGT- } \\
\text { CATTTGTTTTTTCC }\end{array}$ & 235 & 60 & 90.1 \\
\hline TAS1R1 & NC_010448.4 & $\begin{array}{c}\text { Forward: GGAGATCCG- } \\
\text { CAAGGTCAAT } \\
\text { Reverse: GCTGAACTG- } \\
\text { GCGACAACAAT }\end{array}$ & 167 & 58.4 & 101.6 \\
\hline PLCB2 & XM_021097762 & $\begin{array}{c}\text { Forward: CACCACC- } \\
\text { CTTTCTATTACGG } \\
\text { Reverse: TGTTGCCTTC- }\end{array}$ & 239 & 59 & 98.6 \\
\hline ACTB & XM_021086047.1 & $\begin{array}{c}\text { CTCCATCA } \\
\text { Forward: AAGTACTC- } \\
\text { CGTGTGGATCGG } \\
\text { Reverse: ACATCTGCTG- } \\
\text { GAAGGTGGAC }\end{array}$ & 61 & 60 & 102.0 \\
\hline
\end{tabular}

\subsection{Histological Examination}

Testis samples were fixed in $\mathrm{mDF}$ at $4{ }^{\circ} \mathrm{C}$ for $24 \mathrm{~h}$ for histological experiments [17]. The fixed testes were trimmed, subjected to routine histologic processing, and paraffinembedded. The well-fixed paraffin-embedded testis sections were cut at $5 \mu \mathrm{m}$ using a microtome (RM2235; Leica Biosystems Nussloch Gmbh, Nussloch, Germany), mounted on slides coated with 3-aminopropyl-triethoxysilane (APES, 440140; Sigma-Aldrich, St. Louis, $\mathrm{MO}$, USA) and dried for $24 \mathrm{~h}$ at $37^{\circ} \mathrm{C}$. Subsequently, the sections were dewaxed with xylene, hydrated by a gradient ethanol series, and washed in $\mathrm{ddH}_{2} \mathrm{O}$ three times ( $5 \mathrm{~min} / \mathrm{each}$ ). Next, they were stained with hematoxylin and eosin (H\&E, G1120; Solarbio Life Sciences, Beijing, China) according to the manufacturer's protocol. After embedding in neutral resin, the stained sections were viewed under a Nikon C2 Confocal Microscope (Tokyo, Japan). Morphological changes of the testis during postnatal development were evaluated using 12 slices ( 2 slices $/$ testis $\times 2$ testes $\times 3$ animals) at each stage of development. 


\subsection{Immunohistochemistry}

To examine the localization of T1R3, T1R1, gustducin $\alpha-3$ chain (GNAT3) and PLC $\beta 2$ in testes from the Congjiang Xiang pigs at prepuberty (30 day), early puberty (60 day), late puberty ( 90 day), and sexual maturity (120 day), IHC analyses were performed with the streptavidin-biotin complex (SABC) method [21]. Testis samples were fixed in $4 \%$ PFA at $4{ }^{\circ} \mathrm{C}$ for $24 \mathrm{~h}$ and processed in a series of graded ethanol solutions [17]. Testicular sections were deparaffinized and hydrated via graded xylene and ethanol, followed by heat-induced antigen retrieval in $0.01 \mathrm{M}$ citrate buffer $\left(\mathrm{pH}, 6.0\right.$; microwave oven, $100{ }^{\circ} \mathrm{C}$, $5 \mathrm{~min}$ ). To avoid endogenous peroxidase activity and nonspecific antibody staining, the sections were blocked with $3 \% \mathrm{H}_{2} \mathrm{O}_{2}$ in methanol and $5 \%$ bovine serum albumin (BSA, A4737; Sigma-Aldrich, St. Louis, MO, USA) for $1 \mathrm{~h}$ at room temperature. Antibodies for T1R3, T1R1, GNAT3, and PLC $\beta 2$ were diluted in PBS (P1020; Solarbio Life Sciences, Beijing, China) containing $1 \% \mathrm{BSA}$, and the sections were incubated overnight at $4{ }^{\circ} \mathrm{C}$ with primary antibodies (Table 2). A Rabbit IgG-SABC Kit (SA2002; Boster Biological Technology, Wuhan, China) was used to detect the immunoreactivity of these proteins. The immunoreactivity was visualized with 3,3'-diaminobenzidine tetrahydrochloride (DAB) enhanced liquid substrate system (D3939, Sigma-Aldrich, St. Louis, MO, USA) according to the manufacturer's protocol. The negative control sections were incubated with PBS instead of the primary antibody. Finally, the reacted sections were counterstained with hematoxylin solution (G1120; Solarbio Life Sciences, Beijing, China) for $50 \mathrm{~s}$, mounted with coverslips and viewed under a Nikon C2 Confocal Microscope (Tokyo, Japan). Antibodies applied in IHC are listed in Table 2.

Table 2. Antibodies were applied in immunohistochemistry (IHC) and Western blotting (WB).

\begin{tabular}{|c|c|c|c|c|c|}
\hline \multirow{2}{*}{ Manufacturer } & \multirow{2}{*}{ Protein/Name } & \multirow{2}{*}{ Species Origin } & \multirow{2}{*}{ Catalogue No. } & \multicolumn{2}{|c|}{ Dilution * } \\
\hline & & & & WB & IHC \\
\hline Affinity Biosciences & T1R1 & Rabbit & DF10278 & - & - \\
\hline Abcam & T1R3 & Rabbit & ab150525 & $1 / 1000$ & $1 / 150$ \\
\hline Thermo Fisher Scientific & GNAT3 & Rabbit & PA5-50670 & - & - \\
\hline Thermo Fisher Scientific & PLC $\beta 2$ & Rabbit & PA5-75551 & - & $1 / 200$ \\
\hline Affinity Biosciences & $\beta$-actin & Rabbit & AF7018 & $1 / 3000$ & - \\
\hline ABclonal Technology & Second antibody & Rabbit & AC026 & $1 / 5000$ & - \\
\hline Boster Biological Technology & SABC Kit & & SA2002 & - & $1: 300$ \\
\hline
\end{tabular}

Note: * Tris-buffered saline buffer with Tween 20 (TBST) and phosphate-buffered saline (PBS) were used as the dilution of antibodies applied in WB and IHC, respectively.

Antibody staining intensities were determined by three independent observers, following a previously described method [22]. Immunostaining was evaluated using 18 slices ( 3 slices $/$ testis $\times 2$ testes $\times 3$ animals) for each protein at each stage of development.

\subsection{Sodium Dodecyl Sulfate Polyacrylamide Gel Electrophoresis (SDS-PAGE) and WB}

Three animal samples from each time-point passed quality control, and were selected for WB assay. The protein extracts from porcine testes $(80 \mathrm{mg})$ were collected in radioimmunoprecipitation assay (RIPA) buffer (P0013B; Beyotime, Nantong, China) containing $10 \mathrm{mM}$ phenylmethyl-sulfonyl fluoride (PMSF, ST506; Beyotime, Nantong, China) using a FastPrep-24 ${ }^{\mathrm{TM}}$ Classic bead beating grinder and lysis system (MP Biomedicals, Santa Ana, CA, USA). The supernatant was separated and the protein concentration was determined using a Bicinchoninic Acid Protein Assay Kit (PC0020; Solarbio Life Sciences, Beijing, China). Twelve sample lysates $(30 \mu \mathrm{g}, 15 \mu \mathrm{L})$ and a protein standard ladder (P0068; Beyotime, Nantong, China) were separated on a 10\% (w/v) SDS-PAGE gel $(2 \mathrm{~h}, 100 \mathrm{~V}$; P1200; Solarbio Life Sciences, Beijing, China), and then transferred (1.5 h, $100 \mathrm{~V})$ onto a polyvinylidene fluoride membrane (K5AA6843H; Millipore, Bedford, MA, USA).

After hydrating in methanol and deionized $\mathrm{ddH}_{2} \mathrm{O}$, the membrane was blocked with $5 \%$ skimmed milk in Tris-buffered saline buffer with Tween 20 (TBST, 20 mM Tris-buffered 
saline, $0.05 \%$ Tween 20, $\mathrm{pH} 7.5$ ) for $2 \mathrm{~h}$ at room temperature, incubated with diluted T1R3 antibody (ab150525; Abcam, MA, USA) for $16 \mathrm{~h}$ at $4{ }^{\circ} \mathrm{C}$, rinsed three times in TBST, incubated with horseradish peroxidase-linked secondary goat anti-rabbit IgG (AC026; ABclonal Technology, Wuhan, China) at room temperature for $2 \mathrm{~h}$, and then rinsed four times with TBST. All blocks, incubations, and rinses were performed on a rocking platform. Subsequently, protein bands on one blot were detected with Pierce ${ }^{\mathrm{TM}}$ ECL Western Blotting Substrate (400 $\mu \mathrm{L}, 1 \mathrm{~min}$; 32109; Thermo Fisher Scientific, Inc., Waltham, MA, USA) and visualized using the Molecular Imager ChemiDoc XPS+ system (Bio-Rad Laboratories Co., Ltd., CA, USA). To control for loading efficiency, the blots were stripped with Western Blot Stripping Buffer (ab270550; Abcam, MA, USA) at room temperature for $20 \mathrm{~min}$ and re-probed with $\beta$-actin antibody (AF7018; Affinity Biosciences, VIC, Australia). The T1R3 protein bands were normalized to $\beta$-actin. The intensities of immunoreactive bands were evaluated using the ImageJ (http:/ / rsbweb.nih.gov/ij/ (accessed on 29 January 2021)) to quantify the target protein levels by densitometry. Antibodies applied in WB are listed in Table 2.

\subsection{Statistical Analysis}

Results are expressed as means \pm standard deviation (SD). Statistical analyses were performed using GraphPad Prism 8.0.1 (GraphPad Software, Inc., La Jolla, CA, USA). Data were analyzed by one-way analysis of variance (ANOVA) with Tukey's range tests for multiple comparisons between groups. A significant difference was defined as $p<0.05$.

\section{Results}

\subsection{Changes in the Gonadosomatic Index and Testosterone Level during Development}

The testis weight of the Congjiang Xiang pig (Figure 1A) increased from 15 to 180 day $(p<0.0001)$. The testis index increased from 15 to 60 day $(p=0.001)$, with no significant changes thereafter $(p>0.05)$, as shown in Figure 1B. The accelerated increase in the testis weight and testis index at postnatal 60 day corresponded with higher levels of plasma testosterone than those at 15 day $(p=0.0007)$ and 30 day $(p<0.0001)$; plasma testosterone mainly acts via androgen receptors on Sertoli cells to maintain normal testicular function (Figure 2). After completing the first wave of spermatogenesis at 60 day, the testis index and testosterone level showed no changes with age $(p>0.05)$, regardless of the increased testis weight from 60 day to 180 day $(p<0.0001)$, as shown in Figure 2.

\section{A. The testis weight during postnatal development}

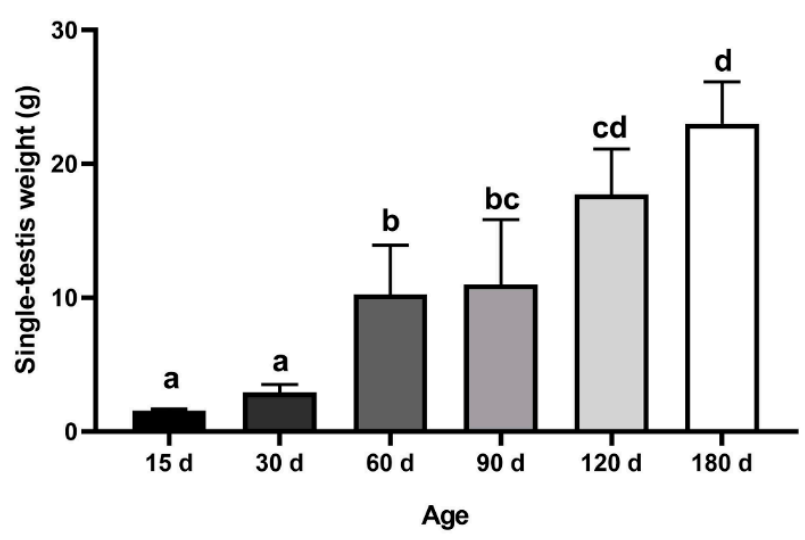

B. The gonadosomatic index during postnatal development

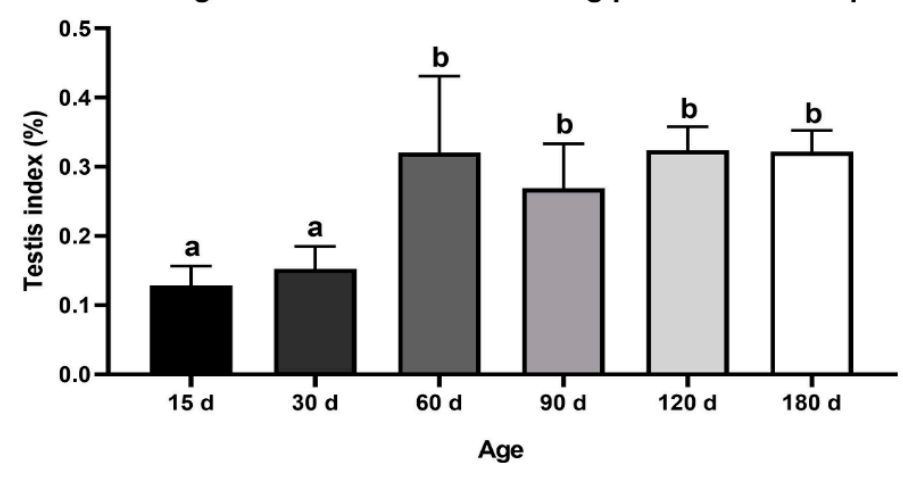

Figure 1. Testis weight and gonadosomatic index during postnatal development of the Congjiang Xiang pig. (A) The testis weight of Congjiang Xiang pigs from 15 day to 180 day. (B) The gonadosomatic index of Congjiang Xiang pigs from 15 day to 180 day was calculated by dividing testis weight by body weight. Measurements are means of left and right testes of a pair. All results are indicated by means $\pm \mathrm{SD}(n \geq 3)$. The data was analyzed by one-way ANOVA with Tukey's multiple comparisons. Values not sharing the same letter $(\mathrm{a}-\mathrm{d})$ denote significant differences among groups $(p<0.05)$. 


\section{Plasma testosterone $(\mathrm{T})$ concentration}

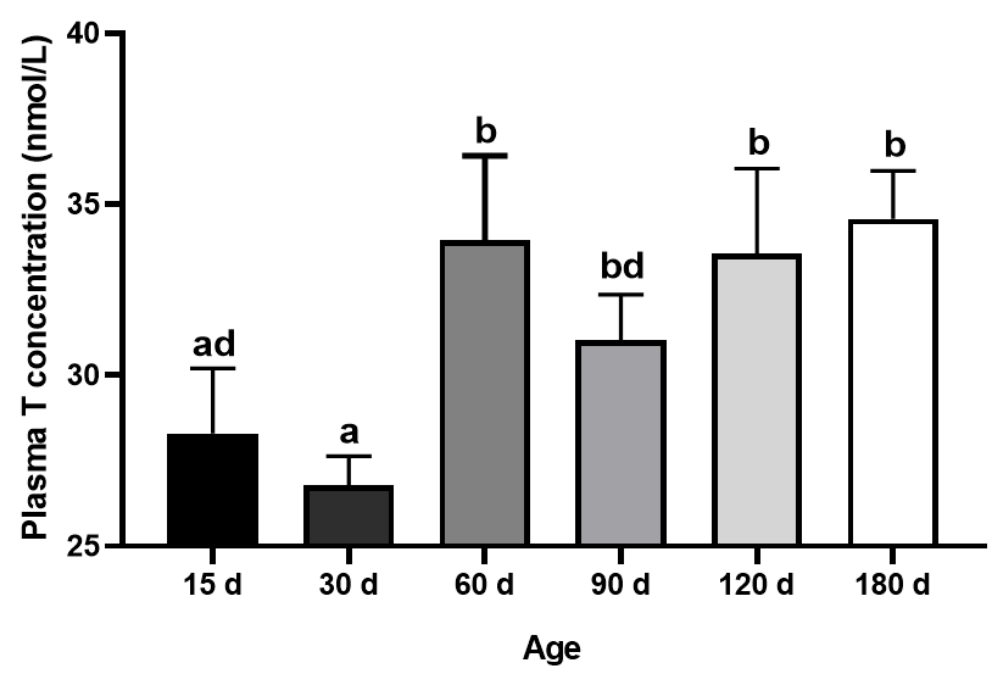

Figure 2. Dynamic changes of plasma testosterone level during postnatal development of the Congjiang Xiang pig. The blood was collected from the jugular vein by a board-certified veterinarian. Results are indicated by means \pm SD $(n \geq 3)$. The data was analyzed by one-way ANOVA with Tukey's multiple comparisons. Values not sharing the same letter $(a, b, d)$ denote significant differences among groups $(p<0.05)$.

\subsection{Morphological Changes in the Testes during Development}

The specific morphological and functional features during testicular ontogeny from 15 day to 180 day are displayed in Figure 3. Consistent with testis weight data, 15-day testes consisting of tubules were lined by spermatogonia types A and B and mitotically active Sertoli cells; the regressing fetal Leydig cells (FLC) were replaced with progenitor Leydig cells (PLC) in a large area of the interstitium (Figure 3A). From 15 day to 30 day, Sertoli cells stopped dividing and spermatocyte development ensued. The lumen was visible in a few tubules with preleptotene, leptotene, zygotene and pachytene spermatocytes, as shown in Figure 3B. The interstitium contained PLC and a small number of immature Leydig cells, which stimulate meiosis. There were no clear morphological differences between FLC, PLC, and immature Leydig cells. After 30 day, pachytene spermatocytes, round spermatids and elongating or elongated spermatids were present in the tubules, and tubule diameters increased at 60 day (Figure 3C). After the first wave of spermatogenesis was complete, the tubular diameter, cell number, and density of elongating spermatids increased gradually from 90 day to 180 day, consistent with the observed changes in testis weight (Figure 3D-F).

According to morphological features, testes weights, and plasma testosterones levels, four development stages were identified in male Congjiang Xiang pigs as follows (Figure 3G): pre-pubertal (15 day, 30 day), early pubertal (60 day), late pubertal (90 day), and sexual maturity (120 day, 180 day). 

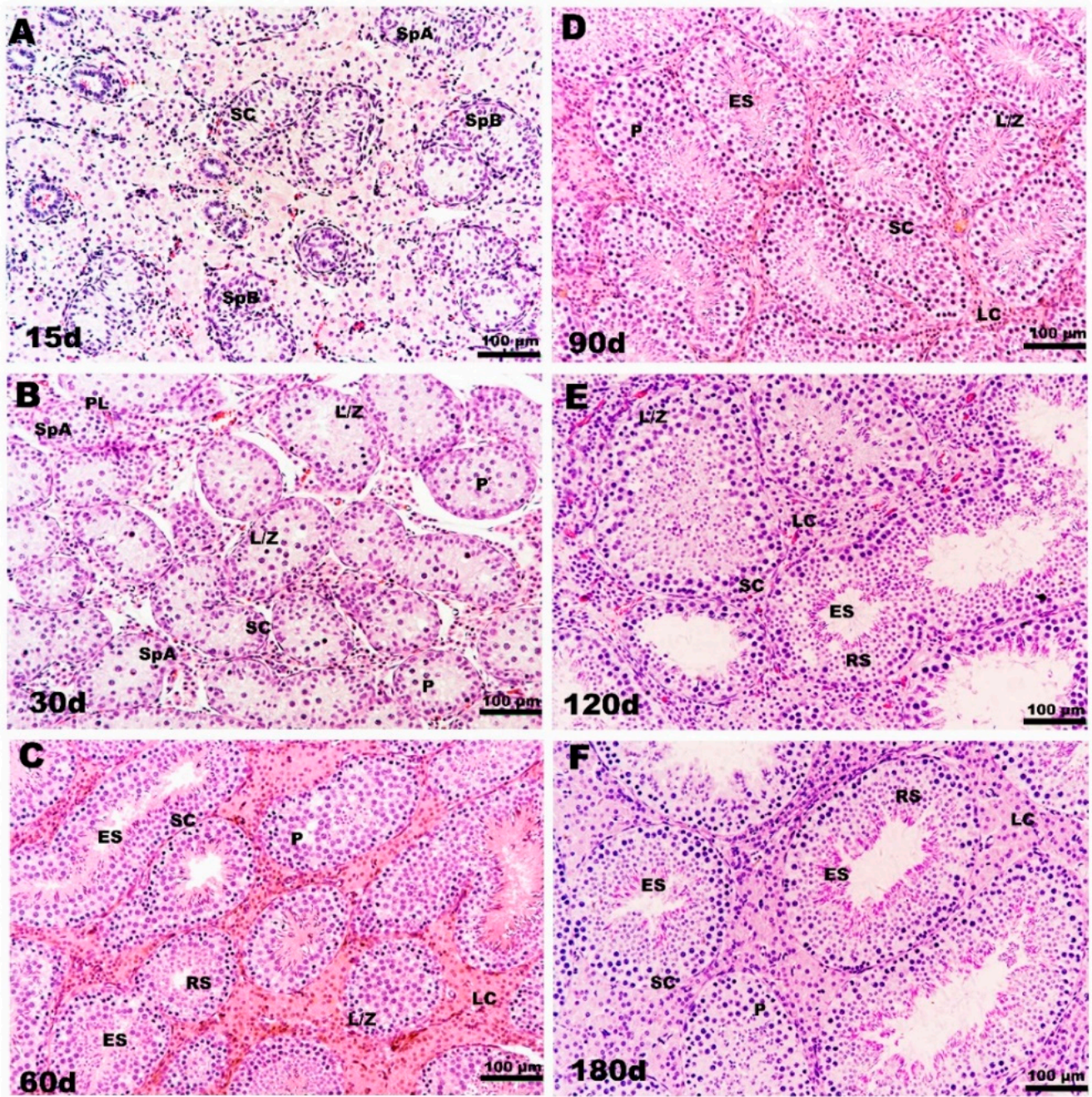

G Schematic illustation of testis developmental emergence of differentiated germ cells in the Congjiang Xiang pig

\begin{tabular}{|c|c|c|c|c|c|c|}
\hline $\begin{array}{l}\text { Age } \\
\text { (d) }\end{array}$ & $\begin{array}{l}\text { Differentiated } \\
\text { spermatognia }\end{array}$ & $\begin{array}{l}\text { primary } \\
\text { spermatocyte }\end{array}$ & $\begin{array}{l}\text { Round } \\
\text { spermatid }\end{array}$ & $\begin{array}{l}\text { Elongated } \\
\text { spermatid }\end{array}$ & $\begin{array}{l}\text { Completed } \\
\text { sperm }\end{array}$ & $\begin{array}{l}\text { Development } \\
\text { stage }\end{array}$ \\
\hline 15 & & & & & & Nenatal \\
\hline 30 & & & & & & Infantile \\
\hline 60 & & & & & & Early pubertal \\
\hline 90 & & & & & & Late pubertal \\
\hline 120 & & & & & & Sexual maturity \\
\hline 180 & & & & & & Sexual maturity \\
\hline
\end{tabular}

Figure 3. Histological observation of testes in Congjiang Xiang pig during development: (A-F) represent 15, 30, 60, 90, 120 and 180-day-old the Congjiang Xiang pig testes $(n=3)$. (G) A schematic illustration of testis development emergence of differentiated germ cells in the Congjiang Xiang pig according to Yomogida K. (2009) [23]. Testes were removed and fixed in mDF $24 \mathrm{~h}$, embedded in paraffin, sectioned $(5 \mu \mathrm{m})$ and stained with Hematoxylin and Eosin using standard procedures. Leydig cells (LC); Sertoli cells (SC); spermatogonia types A (SpA); spermatogonia types B (SpB); leptotene and zygotene spermatocytes (L/Z); preleptotene spermatocytes (PL); pachytene spermatocytes (P); round spermatids (RS); elongating/elongated spermatids (ES). Scale bars (black line in the bottom-right of pictures $): A-F=100 \mu \mathrm{m}(200 \times$ magnification $)$. 


\subsection{Expression of T1R3 and PLC 32 in Testes of Congjiang Xiang Pigs during Postnatal Development}

The T1R3 and $\beta$-actin protein bands were detected at $93 \mathrm{kD}$ and $43 \mathrm{kD}$ in both porcine testes and positive control (Figure S6), indicating the antibodies specificity. Our results showed that the expression of T1R3 increased approximately fivefold from 30 day to 60 day $(p<0.05)$ and remained at a high level until 120 day (Figure 4A,B).
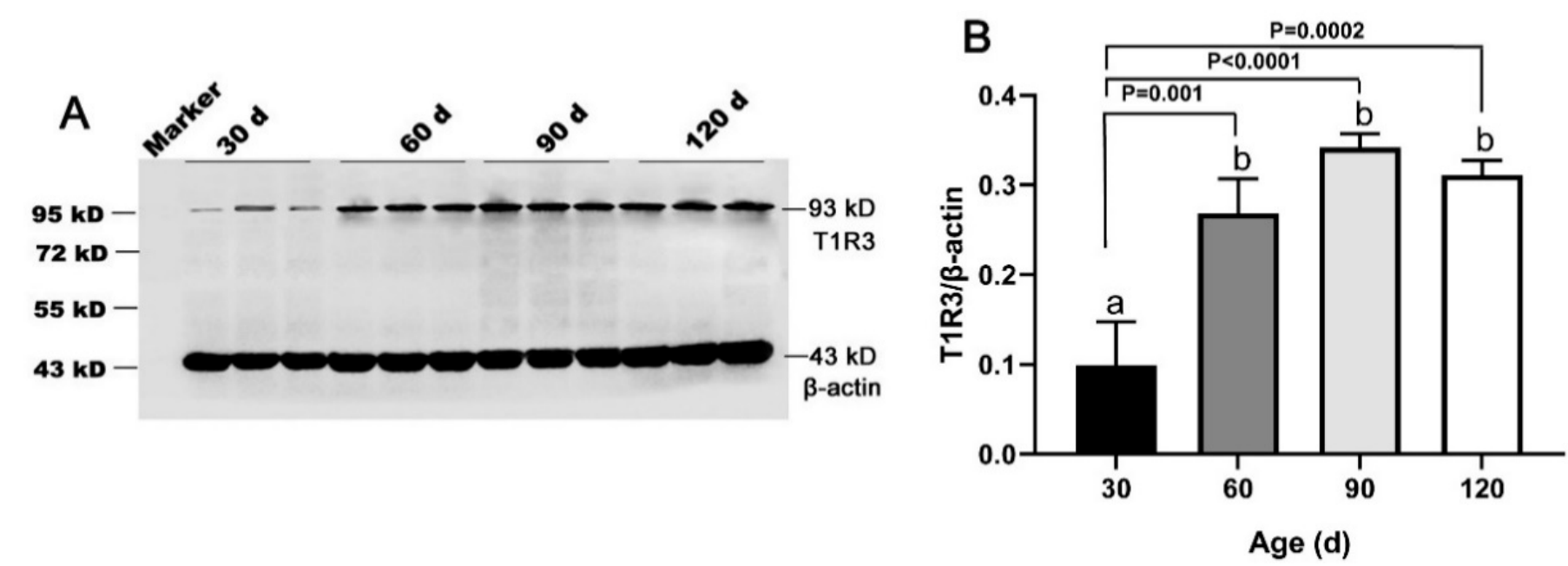

Figure 4. Expression of T1R3 in testes of Congjiang Xiang pigs at four ages. Tissues were collected from pigs at 30, 60, 90, and 120 days old. (A), the protein expression of T1R3 in testes from 30-120 day with western blot. (B), the relative expression of T1R3 from 30 to 120 day analyzed by the Image J. The expression pattern of T1R3 was measured by WB, $\beta$-actin was used as an internal control. The relative expression level was calculated by dividing the T1R3 signal intensity by corresponding $\beta$-actin intensity. Results are indicated by means $\pm \operatorname{SD}(n=3)$. Bars with different letters are significantly different $(p<0.05)$.

T1R3 expression was strong in the testes of Congjiang Xiang pigs, as was the expression of the downstream taste signaling molecule PLC $\beta 2$, when the first spermatogenesis was completed after 60 day (Figures 5 and 6). In addition, Leydig cells expressed the two proteins from 30 day to 120 day. At 30 day, T1R3 protein expression was detected in the Leydig cells rather than in the spermatogonia or Sertoli cells (Figure 5A,A1). However, positive signals for T1R3 were first recorded in the abluminal compartment of 60-day testes, where differentiating spermatids (elongating/elongated spermatids) were located (Figure 5B,B1). After puberty (90 day and 120 day), T1R3 immunoreactivity was recorded during spermatogenesis (Figure 5C,D,C1,D1). Testicular positivity for T1R3 was not detected when slides were incubated with the secondary antibody with the omission of primary antiserum (Figure $5 \mathrm{~F}, \mathrm{~F} 1$ ).

PLC $\beta 2$, downstream of T1R3, showed evident immunolabeling in the spermatogonia, pachytene spermatocytes, and Leydig cells of 30-day testes (Figure 6A,A1). At 60 day, immunopositivity for PLC $\beta 2$ was detected from spermatogonia to elongating/elongated spermatids (Figure 6B,B1). From 90 day to 120 day, PLC $\beta 2$ immunoreaction was clearly observed during spermatogenesis (Figure $6 \mathrm{C}, \mathrm{D}, \mathrm{C} 1, \mathrm{D} 1$ ). No specific staining was detected in the negative control (Figure $6 \mathrm{~F}, \mathrm{~F} 1$ ).

In summary, T1R3 and PLC $\beta 2$ immunolabeling increased gradually from 30 day to 60 day and then remained constant until 120 day. However, commercially available GNAT3 antisera and T1R1 antisera did not yield specific immunolabeling on mouse and pig testis tissues (Figures S4 and S5). 


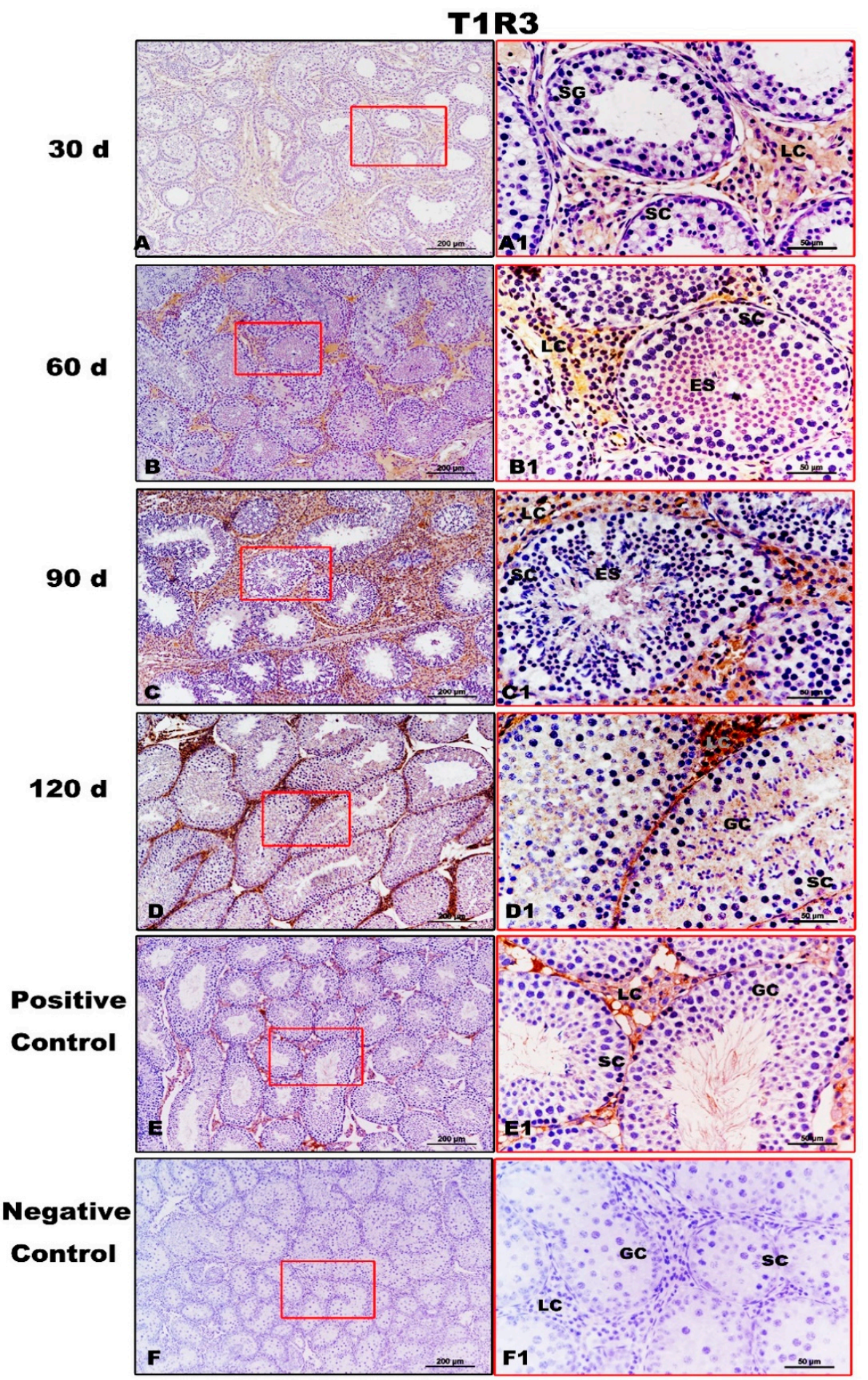

Figure 5. Immunolocalization of T1R3 protein in testes of Congjiang Xiang pigs during development. (A-F) represent the testis sections immunostained with primary antibody of T1R3 in 30-day-old Congjiang Xiang pigs, 60-day-old Congjiang Xiang pigs, 90-day-old Congjiang Xiang pigs, 120-dayold Congjiang Xiang pigs, positive control, and negative control groups ( $n \geq 3$ /group), respectively. Picture (E), the mouse testis sections (at 60 day) were used as a positive control for T1R3. Picture (F), negative control, was performed with PBS instead of the primary antiserum of T1R3 (30 day Congjiang Xiang pig testes). Leydig cells (LC); Sertoli cells (SC); germ cells (GC); spermatogonia (SG); spermatocytes (P); elongating/elongated spermatids (ES). Pictures (A-F) marked by square boxes of red color, the boxes are enlarged beside and marked as (A1-F1). Scale bars: A1-F1 $=200 \mu \mathrm{m}$ $(100 \times$ magnification $), \mathrm{A}-\mathrm{F}=50 \mu \mathrm{m}(400 \times$ magnification $)$. 


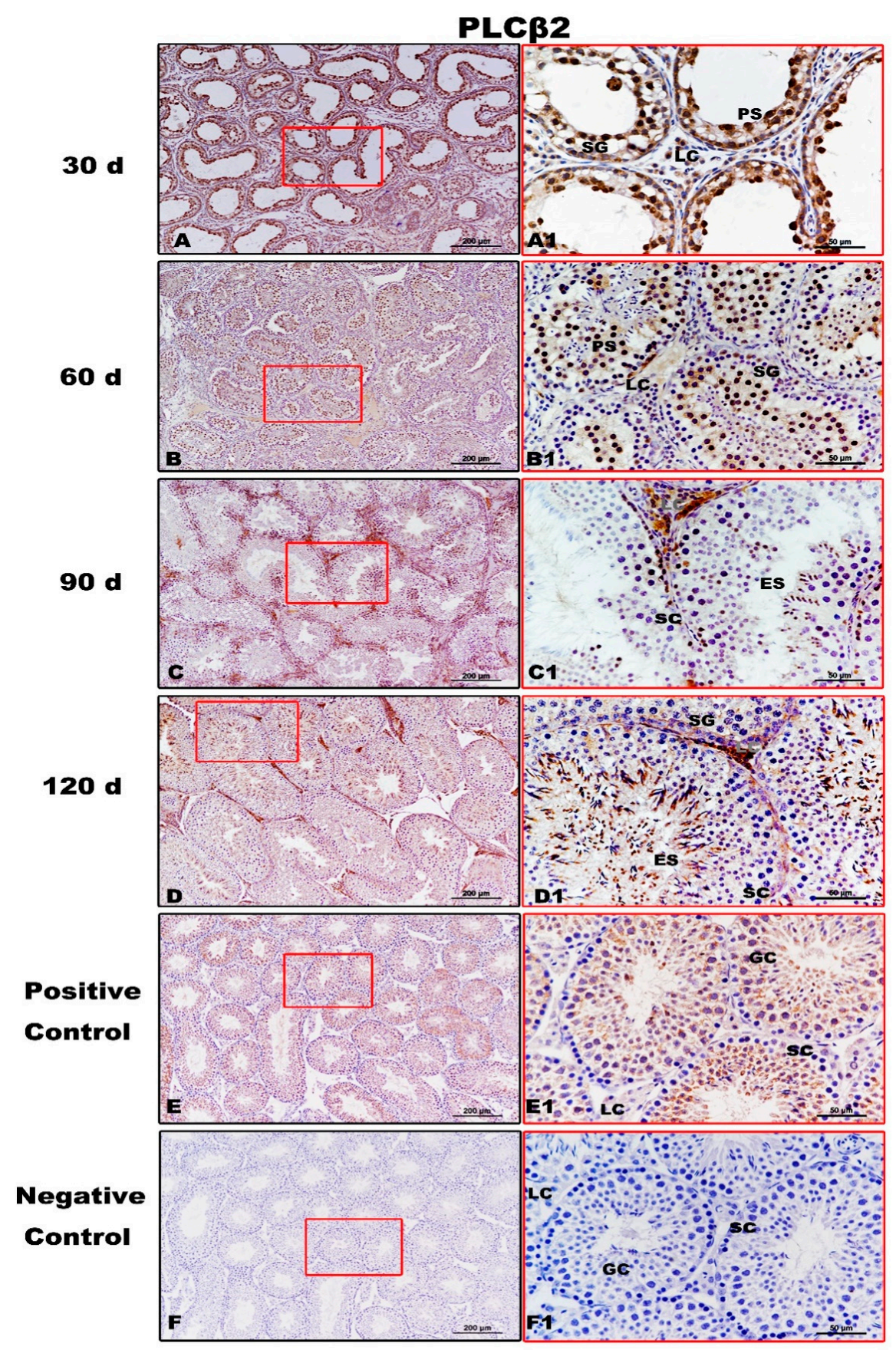

Figure 6. Immunolocalization of PLC $\beta 2$ protein in testes of Congjiang Xiang pigs during development. (A-F) represent the testis sections immunostained with primary antibody of PLC $\beta 2$ in 30-day-old Congjiang Xiang pigs, 60-day-old Congjiang Xiang pigs, 90-day-old Congjiang Xiang pigs, 120-day-old Congjiang Xiang pigs, positive control, and negative control groups ( $n \geq 3$ /group), respectively. Picture (E) the mouse testis sections (at 60 day) were used as a positive control for PLC $\beta 2$. Picture (F) negative control, was performed with PBS instead of the primary antiserum of PLC $\beta 2$ (60 day mouse testes). Leydig cells (LC); Sertoli cells (SC); germ cells (GC); spermatogonia (SG); spermatocytes (P); elongating/elongated spermatids (ES). Pictures (A1-F1) are marked by square boxes of red color which are enlarged beside and marked as (A1-F1). Scale bars: A-F $=200 \mu \mathrm{m}$ (100× magnification), A1-F1 = $50 \mu \mathrm{m}$ (400× magnification).

\subsection{Expression of T1R3 and PLC $\beta 2$ during the Spermatogenic Cycle}

To investigate whether T1R3 and PLC $\beta 2$ affected the spermatogenic cycle in Congjiang Xiang pigs, we analyzed their expression patterns in 120 day testes during the 8 th of the 
spermatogenic cycle [21]. Throughout the spermatogenic cycle, the expression levels of T1R3 and PLC $\beta 2$ on the spermatogenic epithelium at stages II-VI, were higher than those at stages I, VII, and VIII (Figure 7). When round spermatids at stage I transformed into elongating/elongated spermatids at stages II-VI, T1R3 was significantly expressed in the cytoplasm of elongating/elongated spermatids, and the immunoreactions in these cells were higher than those in spermatogonia, leptotene/zygotene/pachytene/diplotene spermatocytes, and Sertoli cells at stages I-VI (Figure 7A1-A6). When the elongated spermatids were released at the luminal portion of the seminiferous tubule, residual bodies with strong T1R3 expression were observed at stages VII-VIII, and T1R3 was also detected at the flagella of elongated spermatids (Figure 7A7,A8).

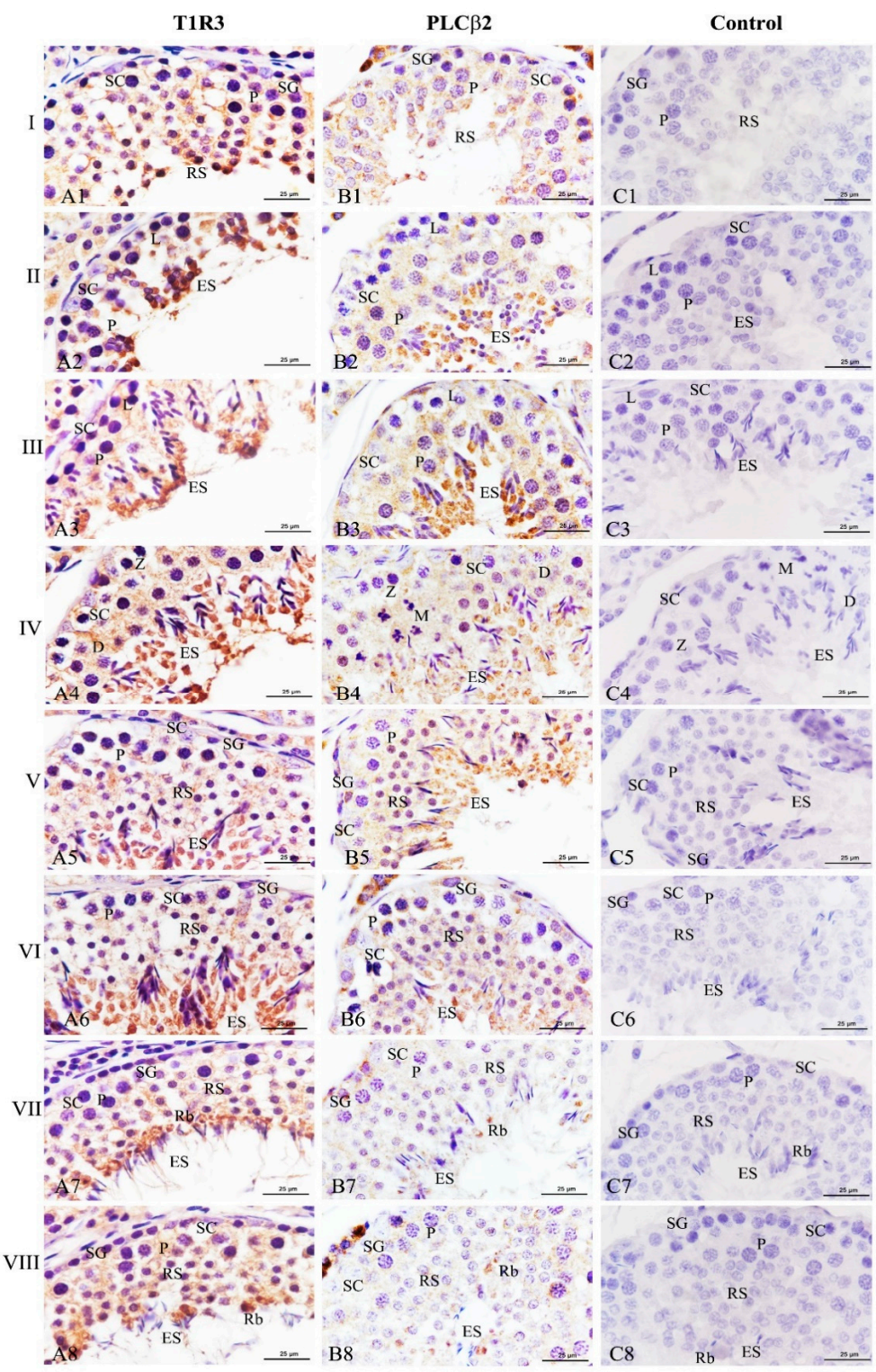

Figure 7. Expression of T1R3 and PLC $\beta 2$ during the spermatogenic cycle at 120 days in the testes of the Congjiang Xiang pig. Positive immunostaining in brown, and counterstaining with hematoxylin $(n=3)$. (A1-A8) represent immunostaining of T1R3 antibodies at stages I-VIII. (B1-B8) represent immunostaining of PLC $\beta 2$ antibodies at stages I-VIII. (C1-C8) represent negative control at stages I-VIII, which was performed with PBS instead of primary antibody. Leydig cells (LC); Sertoli cells (SC); spermatogonia (SG); leptotene and zygotene spermatocytes (L/Z); preleptotene spermatocytes (PL); pachytene spermatocytes (P); round spermatids (RS); elongating/elongated spermatids (ES); residual bodies $(\mathrm{Rb})$. Scale bars: A1-A8 = $25 \mu \mathrm{m}$ (1000× magnification); B1-B8 = $25 \mu \mathrm{m}(1000 \times$ magnification); $\mathrm{C} 1-\mathrm{C} 8=25 \mu \mathrm{m}$ (1000 $\times$ magnification). 
Simultaneously, PLC $\beta 2$ exhibited a similar change from stages I-VI (Figure 7B1-B6). Although a significant decrease of this protein expression was found at stages VII-VIII, it is remarkable that PLC $\beta 2$ was only localized at the residual bodies (Figure 7B7,B8). No specific staining was detected in the negative control (Figure 7C,C1).

\section{5. mRNA Expression of Umami Taste-Related Molecules in Testes of Congjiang Xiang Pigs during Development}

As an umami/amino acid receptor, T1R3 combines with T1R1 to regulate $\mathrm{Ca}^{2+}$ signaling via PLC $\beta 2$. These three proteins are encoded by TAS1R1, TAS1R3, and PLCB2, respectively (Figure $8 \mathrm{~A}$ ). As determined by q-PCR, the mRNA levels of these three genes were low in the testis at 30 day (pre-pubertal stage), increased substantially from 30 day to 60 day (early pubertal stage), and then remained steady until 120 day (sexual maturity) (Figure $8 \mathrm{~B}-\mathrm{D}$ ). These findings agreed with the results of protein-level analyses. In addition, we did not detect the transcription of TAS1R2 or GNAT3 in Congjiang Xiang pig testes (Figure S7).

A

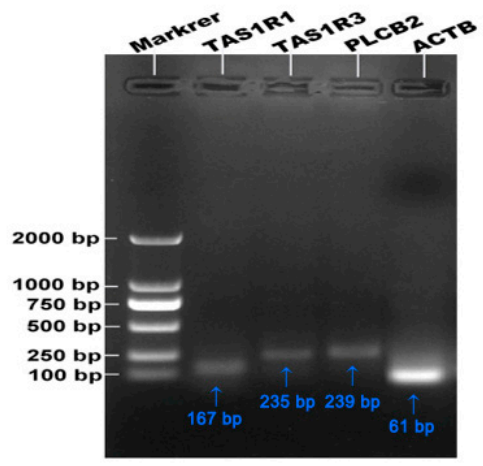

TAS1R3 mRNA Expression

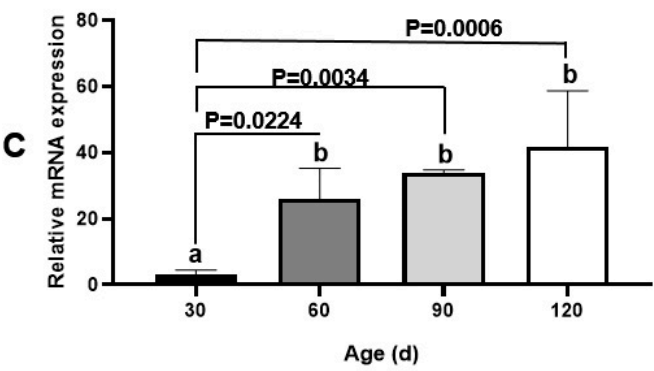

B
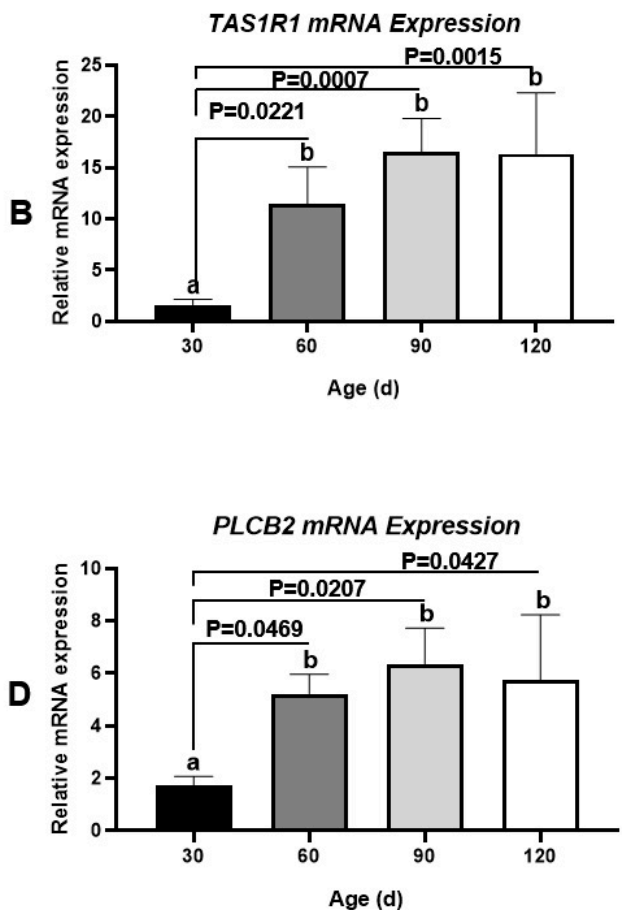

Figure 8. Transcription changes of umami tasting molecules, TAS1R1, TAS1R3 and PLCB2 during testis development of the Congjiang Xiang pig, evidenced by q-PCR. Gel electrophoresis q-PCR result of TAS1R1 (167 bp), TA1SR3 (235 bp), and PLCB2 (239 bp), respectively. The mRNA levels of target genes were normalized with housekeeping gene $(A T C B, 61 \mathrm{bp})$ and expressed as $2^{-\triangle \Delta C T}$ using samples on day 30 as calibrator. Results are indicated by means $\pm \mathrm{SD}(n=3)$. Values not sharing the same letter $(a, b)$ denote significant differences among groups $(p<0.05)$.

\section{Discussion}

In mammals, T1R3 plays a key role in sweet or umami perception along with T1R2 or T1R1, respectively, and transduces a common signaling cascade, $\mathrm{G}_{\text {gust }}-\mathrm{PLC} \beta 2-\mathrm{TRMP5}-\mathrm{Ca}^{2+}$, for the evaluation of foods [24]. Recent studies have demonstrated that this "tasting" locus is widely expressed from the mouse tongue to the testis; however, the precise roles of the taste receptor in the testis are unclear [8]. To elucidate the expression pattern of testicular T1R3 during testis development in the Congjiang Xiang pig, four key development stages were identified (pre-puberty, 30 day; early puberty, 60 day; late puberty, 90 day; sexual maturity, 120 day) in the present study, according to testicular parameters and testosterone 
levels [25]. The four developmental time-points were earlier than those of micro-minipigs (pre-pubertal 45 day; pubertal 90 day; and sexually mature 135 day) [26].

The expression of T1R3 in the porcine testes increased significantly from 30 day (prepuberty) to 60 day (early puberty), and remained high until 120 day (sexual maturity) along with PLC $\beta 2$, and only the expression levels of T1R1 at mRNA level were similar to those of T1R3. An IHC analysis showed that the strong expressions of testicular T1R3/PLC $\beta 2$ were detected at the cytoplasm of elongating/elongated spermatids and Leydig cells. The observed T1R3 expression pattern was consistent with the results of our previous study of mice [11]. The expression pattern of T1R3 and its related taste signaling components in germ cells and their potential functions have mainly been reported in mice $[6,9,10,12,27,28]$. The components of sweet/umami taste-related signaling cascades, such as T1R1, T1R2, T1R3, $G_{\alpha \text { gust }}, G_{\gamma 13 \text { gust }}$, PLC $\beta 2$, and TRMP5, have been detected in spermatogenic cells of mice, in some cases, these molecules have been observed in the testicular basal layer, Leydig cells and epididymal spermatozoa [7,8]. Using a double-knockout mouse line, Mosinger et al. (2013) showed that the absence of both T1R3 and $G_{\alpha g u s t}$ leads to male-specific sterility [10]. The double-null mice display exfoliated spermatids and numerous giants and pyknotic cells in the testicular tubule lumen as well as immature cells in the epididymis and nonmotile sperm, which are related to impaired cAMP-regulated gene transcription (CREM) [10]. These data indicate that T1R3 and $\mathrm{G}_{\alpha \text { gust }}$ are functionally crucial in spermiogenesis, sperm development, and maturation. It is likely that mouse T1R3 acts in concert with T1R1, as Tas1r1 deficient mice show spermatogenic abnormalities (e.g., an increase in multinucleated giant cells and miss-located spermatocytes) and increased apoptosis during spermatogenesis [6,9]. The Tas1r1 null-mutant sperm show increased spontaneous acrosome reactions as well as increased intracellular $\mathrm{Ca}^{2+}$ and cAMP levels [6]. Therefore, it was remarkable that apart from T1R3, the umami/sweet taste-related signaling component PLC $\beta 2$ was detected in porcine testes, in addition to the mRNA expression of T1R1. These data provide evidence that T1R3 could contribute to the signaling in the mammalian testis.

Interestingly, increases in testicular T1R3, T1R1, and PLC $\beta 2$ levels are in accordance with significant increases in plasma testosterone and the testis index from 30 day to 60 day. In the testis, the changes in testosterone are related to the fate of Leydig cells from the postnatal period to puberty. In mice, a four-stage model of Leydig cell development has been identified and characterized as fetal to progenitor to immature to mature Leydig cells, and only fetal and immature Leydig cells produce testosterone [29,30]. Similarly, there was significant testicular steroidogenic activity in newborn male pigs, and testicular steroid levels declined dramatically at the prepubertal stage (2 to 5 months) [31]. When Leydig cells reach final maturation, the secretion of testosterone is equal to that in the adult stage [31]. Apart from seminiferous tubules, T1R3 and PLC $\beta 2$ were mainly localized in testicular Leydig cells of the Congjiang Xiang pig; however, the role of these proteins in Leydig cell development remains unknown. We have previously shown that mouse testis weights and testosterone levels increase with the up-regulation of key molecules involved in testicular sweet/umami taste (T1R3 and $\mathrm{G}_{\alpha \text {-gust }}$ ) and steroidogenesis (steroidogenic acute regulatory protein, StAR, etc.) after administration of saccharin sodium in mouse food and drink [12]. Steroidogenesis is essential for normal testis development and function. In Leydig cells, luteinizing hormone (LH) secreted by the pituitary binds to the LH receptor (LHCGR) to induce a LHCGR-complex interaction, which activates the cAMP cascade to initiate a classical steroidogenic pathway [32-34]. Therefore, we speculate that in addition to increased testosterone in the plasma, high levels of T1R3 and PLC $\beta 2$ in the testis after puberty may be related to the regulation of steroidogenesis in Leydig cells via the T1R3PLC $\beta 2$ pathway. A better understanding of gene regulation in testicular Leydig cells development and spermiogenesis may provide a basis for limiting the incidence of male reproductive pathologies caused by the dysfunction of Leydig cells [35].

In addition, the localization of T1R3 and PLC $\beta 2$ in the cytoplasm of elongating or elongated spermatids in Congjiang Xiang pigs as well as residual bodies was consistent 
with previous results for mice [11]. However, the role of T1R3 coupled with T1R1 and PLC $\beta 2$ in residual bodies needs to be clarified in the future.

The minipig is considered a convenient animal model for preclinical studies because they rapidly achieve sexual maturity (before the age of six months) and the duration of the spermatogenic cycle is short (i.e., 35 day) [36]. Although there are structural variations at the genome level between relatively large litter sizes (average litter size: 13 piglets) and small litter sizes (average litter size: 8 piglets) in Congjiang Xiang pigs for long-term grazing and inbreeding [37,38], the breed is clearly characterized by early sexual maturity $[39,40]$. According to our study, Congjiang Xiang pigs exhibit the onset of puberty at approximately 2 months [40], similar to Gottingen pigs, and earlier than Yucatan minipigs (3.6-4 months) and Yorkshire (around 6 months) [41]. The testes of Yorkshire pigs are remarkably active in steroidogenesis with a peak at $14-28$ days (about $5-10 \mathrm{nmol} / \mathrm{L}$ ) after birth, remain at low activity from 60 to 150 day $(2-5 \mathrm{nmol} / \mathrm{L})$ and increase steroidogenic activity thereafter (6 months: 10-20 nmol/L) [42]. During testis development, serum testosterone levels increase sharply at the prepubertal to pubertal phase in male mammals [43]. In the present study, the plasma testosterone levels were also low in the prepubertal period of Congjiang Xiang boars, increased substantially between 30 day and 60 day old (about $26-37 \mathrm{nmol} / \mathrm{L}$ ), and remained high thereafter ( 6 months: $32-36 \mathrm{nmol} / \mathrm{L}$ ). In addition, the early age of the postnatal period is stable, despite a low trend of plasma testosterone from 15 day to 30 day, probably due to the regression of FLCs and the development of PLCs that dominantly produce dihydrotestosterone and $3 \alpha$-androstanediol, rather than testosterone [29]. Low testosterone does not preclude spermatogonia development, and the increase in testis weight slows during this period. In summary, these data confirmed that the change in plasma testosterone levels was closely associated with testis development in Congjiang Xiang pigs.

\section{Conclusions}

Our results provide clear evidence for the expression of T1R1, T1R3, and PLC $\beta 2$ in the porcine testis. T1R3 and PLC $\beta 2$ were expressed in both tubular and interstitial compartments of the testis during postnatal development. The expression levels of T1R3 and PLC $\beta 2$ increased from 30 to 60 day and remained high until 120 day. During the spermatogenic cycle, the two proteins exhibited the stage- and cell-specific expression patterns; the expression levels at stages II-VI were higher than those at other stages, while late spermatids and residual bodies expressed much higher levels than those of other cells in the seminiferous epithelium. These data indicate a possible role of T1R3 in the regulation of spermatid differentiation and Leydig cell function. The precise roles of testicular T1R3 and the related taste signaling component PLC $\beta 2$ need to be clarified in the future.

Supplementary Materials: The following are available online at https:/ / www.mdpi.com/2076-261 5/11/2/437/s1. Figure S1: The quality of the total RNA samples extracted from Congjiang Xiang pig tests measured by RNA electrophoresis; Figure S2: Ct values of four candidate housekeeping genes across testis sample at 30-90 day; Figure S3: The amplification and standard curve of TAS1R3, TAS1R1, PLCB2 and ACTB in Q-PCR experiment; Figure S4: Expression of T1R1 and GNAT3 in testes of Congjiang Xiang pigs at 30, 60, 90 and 120 days old; Figure S5: Immunolocalization of T1R1 and GANT3 proteins in testes of Congjiang Xiang pigs and mice; Figure S6: WB experiment of T1R3 antibody in the Congjiang Xiang pig testes at 30-120 day; Figure S7: Transcription of TAS1R1, TAS1R2, GNAT3 and PLCB2 in the adult Congjiang Xiang pigs; Table S1: Yields and purity of total RNA measured with NanoDrop; Table S2: The Ct values of four housekeeping genes during developmental stages of porcine testis.

Author Contributions: Conceptualization, T.G.; methodology, T.G.; validation, T.G. and W.W.; formal analysis, Y.Y.; investigation, W.W., L.M., Y.X., Z.L., S.W. and Q.M.; resources, T.G., Y.Y. and W.W.; data curation, T.G. and W.W.; writing—original draft preparation, T.G.; writing-review and editing, H.X. and X.C.; visualization, T.G. and W.W.; supervision, H.X.; project administration, H.X. and X.C.; funding acquisition, T.G. All authors have read and agreed to the published version of the manuscript. 
Funding: This research was funded by the National Natural Science Foundation of China, grant number 31702117; the Science and Technology project of Guizhou Province, grant numbers QKHJC [2018]1404, QKHPTRC[2018]5436, QKHJC[2020]1Y135 and QKHJC[2020]1Z028; the Scientific Research Cooperation Project with America and Oceania Region, Ministry of Education, grant number JWSM[2016]2191.

Institutional Review Board Statement: The study was conducted according to the Regulations for the Administration of Affairs Concerning Experimental Animals approved by the State Council of the People's Republic of China (No. 588, revised 2017). All experimental procedures in the present study were approved by the Institutional Animal Care and Use Committee of Guizhou Medical University (No. 1801227, Guiyang, China; 2018/09/13) and the Guizhou University Experimental Animal Ethics (No. EAE-GZU-2020-P001, Guiyang, China; 8 January 2020).

Informed Consent Statement: Not applicable.

Data Availability Statement: The data presented in this study are available on request from the corresponding author.

Acknowledgments: The authors express their appreciation to Yong Zhang (College of Animal science, Guizhou University, China) and for the sampling assistance.

Conflicts of Interest: The author declares no conflict of interest is present in this manuscript. The funders had no role in the design of the study; in the collection, analyses, or interpretation of data; in the writing of the manuscript, or in the decision to publish the results.

\section{References}

1. Nuemket, N.; Yasui, N.; Kusakabe, Y.; Nomura, Y.; Atsumi, N.; Akiyama, S.; Hosotani, M. Structural basis for perception of diverse chemical substances by T1r taste receptors. Nat. Commun. 2017, 8, 1-10. [CrossRef]

2. Ekstrand, B.; Young, J.F.; Rasmussen, M.K. Taste receptors in the gut-A new target for health promoting properties in diet. Food Res. Int. 2017, 100, 1-8. [CrossRef] [PubMed]

3. Kiuchi, S.; Yamada, T.; Kiyokawa, N.; Saito, T.; Fujimoto, J.; Yasue, H. Genomic structure of swine taste receptor family 1 member 3, TAS1R3, and its expression in tissues. Cytogenet. Genome Res. 2006, 115, 51-61. [CrossRef]

4. Li, F. Taste perception: From the tongue to the testis. Mol. Hum. Reprod. 2013, 19, 349-360. [CrossRef] [PubMed]

5. Governini, L.; Semplici, B.; Pavone, V.; Crifasi, L.; Marrocco, C.; De Leo, V.; Piomboni, P. Expression of taste receptor 2 subtypes in human testis and sperm. J. Clin. Med. 2020, 9, 264. [CrossRef]

6. Meyer, D.; Voigt, A.; Widmayer, P.; Borth, H.; Huebner, S.; Breit, A.; Marschall, S.; de Angelis, M.H.; Boehm, U.; Meyerhof, W.; et al. Expression of Tas1 taste receptors in mammalian spermatozoa: Functional role of Tas1r1 in regulating basal $\mathrm{Ca}^{2+}$ and cAMP concentrations in spermatozoa. PLoS ONE 2012, 7, e32354. [CrossRef]

7. Feng, L.; Minliang, Z. Depletion of bitter taste transduction leads to massive spermatid loss in transgenic mice. Mol. Hum. Reprod. 2012, 18, 289-297.

8. Lee, S.J.; Depoortere, I.; Hatt, H. Therapeutic potential of ectopic olfactory and taste receptors. Nat. Rev. Drug Discov. 2019, 18, 116-138. [CrossRef]

9. Luddi, A.; Governini, L.; Wilmskötter, D.; Gudermann, T.; Boekhoff, I.; Piomboni, P. Taste receptors: New players in sperm biology. Int. J. Mol. Sci. 2019, 20, 967. [CrossRef] [PubMed]

10. Mosinger, B.; Redding, K.M.; Parker, M.R.; Yevshayeva, V.; Yee, K.K.; Dyomina, K.; Li, Y.; Margolskee, R.F. Genetic loss or pharmacological blockade of testes-expressed taste genes causes male sterility. Proc. Natl. Acad. Sci. USA 2013, 110, 12319-12324. [CrossRef] [PubMed]

11. Gong, T.; Wei, Q.W.; Mao, D.G.; Shi, F.X. Expression patterns of taste receptor type 1 subunit 3 and $\alpha$-gustducin in the mouse testis during development. Acta Histochem. 2016, 118, 20-30. [CrossRef] [PubMed]

12. Gong, T.; Wei, Q.W.; Mao, D.G.; Nagaoka, K.; Watanabe, G.; Taya, K.; Shi, F.X. Effects of daily exposure to saccharin and sucrose on testicular biologic functions in mice. Biol. Reprod. 2016, 95, 1-13. [CrossRef] [PubMed]

13. Liu, P.; Liu, R.; Zhang, Q. Chinese Xiang Pig; China Agriculture Press: Beijing, China, 2010.

14. Tang, L.T.; Ran, X.Q.; Mao, N.; Zhang, F.P.; Niu, X.; Ruan, Y.Q.; Wang, J.F. Analysis of alternative splicing events by RNA sequencing in the ovaries of Xiang pig at estrous and diestrous. Theriogenology 2018, 119, 60-68. [CrossRef] [PubMed]

15. Luo, Z.Y.; Dai, X.L.; Ran, X.Q.; Cen, Y.X.; Niu, X.; Li, S.; Huang, S.H.; Wang, J.F. Identification and profile of microRNAs in Xiang pig testes in four different ages detected by Solexa sequencing. Theriogenology 2018, 117, 61-71. [CrossRef]

16. Lerman, L.O.; Kurtz, T.W.; Touyz, R.M.; Ellison, D.H.; Chade, A.R.; Crowley, S.D.; Mattson, D.L.; Mullins, J.J.; Osborn, J.; Eirin, A. Animal models of hypertension: A scientific statement from the American Heart Association. Hypertension 2019, 73, e87-e120. [CrossRef] [PubMed]

17. Wang, W.Y.; Meng, L.J.; Xu, Y.J.; Gong, T.; Yang, Y. Effects of 4\% paraformaldehyde and modified Davidson's fluid on the morphology and immunohistochemistry of Xiang pig testes. J. Toxicol. Pathol. 2020, 33, 97-104. [CrossRef] 
18. Fleige, S.; Pfaffl, M.W. RNA integrity and the effect on the real-time qRT-PCR performance. Mol. Aspects Med. 2006, 27, 126-139. [CrossRef]

19. Nygard, A.B.; Jørgensen, C.B.; Cirera, S.; Fredholm, M. Selection of reference genes for gene expression studies in pig tissues using SYBR green qPCR. BMC Mol. Biol. 2007, 8, 67. [CrossRef]

20. Livak, K.J.; Schmittgen, T.D. Analysis of relative gene expression data using real-time quantitative PCR and the $2^{-\Delta \Delta C T}$ method. Methods 2001, 25, 402-408. [CrossRef] [PubMed]

21. King, G.; Payne, S.; Walker, F.; Murray, G.I. A highly sensitive detection method for immunohistochemistry using biotinylated tyramine. J. Pathol. 1997, 183, 237-241. [CrossRef]

22. Wei, Q.W.; Ding, W.; Shi, F.X. Roles of poly (adp-ribose) polymerase (parp1) cleavage in the ovaries of fetal, neonatal, and adult pigs. Reproduction 2013, 146, 593-602. [CrossRef] [PubMed]

23. Yomogida, K. Electroporation and Sonoporation in Developmental Biology; Springer: Tokyo, Japan, 2009; pp. $271-283$.

24. Liman, E.R.; Zhang, Y.V.; Montell, C. Peripheral coding of taste. Neuron 2014, 81, 984-1000. [CrossRef] [PubMed]

25. Ren, D.; Xing, Y.; Lin, M.; Wu, Y.; Li, K.; Li, W.; Yang, S.; Guo, T.; Ren, J.; Ma, J. Evaluations of boar gonad development, spermatogenesis with regard to semen characteristics, libido and serum testosterone levels based on large White Duroc $\times$ Chinese Erhualian crossbred boars. Reprod. Domest. Anim. 2009, 44, 913-919. [CrossRef] [PubMed]

26. Kangawa, A.; Otake, M.; Enya, S.; Yoshida, T.; Shibata, M. Histological changes of the testicular interstitium during postnatal development in microminipigs. Toxicol. Pathol. 2019, 47, 469-482. [CrossRef]

27. Frolikova, M.; Otcenaskova, T.; Valasková, E.; Postlerova, P.; Stopkova, R.; Stopka, P.; Komrskova, K. The Role of Taste Receptor mTAS1R3 in Chemical Communication of Gametes. Int. J. Mol. Sci. 2020, 21, 2651. [CrossRef] [PubMed]

28. Spinaci, M.; Bucci, D.; Gadani, B.; Porcu, E.; Tamanini, C.; Galeati, G. Pig sperm preincubation and gamete coincubation with glutamate enhance sperm-oocyte binding and in vitro fertilization. Theriogenology 2017, 95, 149-153. [CrossRef] [PubMed]

29. Picut, C.A.; Remick, A.K.; de Rijk, E.P.; Simons, M.L.; Stump, D.G.; Parker, G.A. Postnatal development of the testis in the rat: Morphologic study and correlation of morphology to neuroendocrine parameters. Toxicol. Pathol. 2015, 43, 326-342. [CrossRef] [PubMed]

30. Inoue, M.; Baba, T.; Morohashi, K.i. Recent progress in understanding the mechanisms of Leydig cell differentiation. Mol. Cell. Endocrinol. 2018, 468, 39-46. [CrossRef]

31. Lervik, S.; Oskam, I.; Krogenæs, A.; Andresen, O.; Dahl, E.; Haga, H.A.; Tajet, H.; Olsaker, I.; Ropstad, E. Androsterone and testosterone levels and testicular morphology of Duroc boars related to estimated breeding value for androsterone. Theriogenology 2013, 79, 986-994. [CrossRef]

32. Cormier, M.; Ghouili, F.; Roumaud, P.; Bauer, W.; Touaibia, M.; Martin, L.J. Influences of flavones on cell viability and cAMPdependent steroidogenic gene regulation in MA-10 Leydig cells. Cell Biol. Toxicol. 2018, 34, 23-38. [CrossRef]

33. Poderoso, C.; Duarte, A.; Cooke, M.; Orlando, U.; Gottifredi, V.; Solano, A.R.; Lemos, J.R.; Podestá, E.J. The spatial and temporal regulation of the hormonal signal. Role of mitochondria in the formation of a protein complex required for the activation of cholesterol transport and steroids synthesis. Mol. Cell. Endocrinol. 2013, 371, 26-33. [CrossRef]

34. Hu, X.; Go, Y.M.; Jones, D.P. Omics integration for mitochondria systems biology. Antioxid. Redox Signal. 2020, 32, 853-872. [CrossRef] [PubMed]

35. Martin, L.J. Cell interactions and genetic regulation that contribute to testicular Leydig cell development and differentiation. Mol. Reprod. Dev. 2016, 83, 470-487. [CrossRef] [PubMed]

36. Bode, G.; Clausing, P.; Gervais, F.; Loegsted, J.; Luft, J.; Nogues, V.; Sims, J. The utility of the minipig as an animal model in regulatory toxicology. Pharmacol. Toxicol. Methods 2010, 62, 196-220. [CrossRef] [PubMed]

37. Liu, C.; Ran, X.; Wang, J.; Li, S.; Liu, J. Detection of genomic structural variations in Guizhou indigenous pigs and the comparison with other breeds. PLoS ONE 2018, 13, e0194282. [CrossRef] [PubMed]

38. Liu, C.; Ran, X.; Yu, C.; Xu, Q.; Niu, X.; Zhao, P.; Wang, J. Whole-genome analysis of structural variations between Xiang pigs with larger litter sizes and those with smaller litter sizes. Genomics 2019, 111, 310-319. [CrossRef] [PubMed]

39. Huang, M.; Yang, B.; Chen, H.; Zhang, H.; Wu, Z.; Ai, H.; Ren, J.; Huang, L. The fine-scale genetic structure and selection signals of Chinese indigenous pigs. Evol. Appl. 2020, 13, 458-475. [CrossRef]

40. Meng, L.J.; Wang, W.Y.; Xu, Y.J.; Gong, T.; Yang, Y. Postnatal differentiation and regional histological variations in the ductus epididymidis of the Congjiang Xiang pig. Tissue Cell 2020, 67, 101411. [CrossRef]

41. Howroyd, P.C.; Peter, B.; de Rijk, E. Review of sexual maturity in the minipig. Toxicol. Pathol. 2016, 44, 607-611. [CrossRef]

42. Schwarzenberger, F.; Toole, G.S.; Christie, H.L.; Raeside, J.I. Plasma levels of several androgens and estrogens from birth to puberty in male domestic pigs. Eur. J. Endocrinol. 1993, 128, 173-177. [CrossRef]

43. França, L.R.; Silva, V.A., Jr.; Chiarini, H.; Garcia, S.K.; Debeljuk, L. Cell proliferation and hormonal changes during postnatal development of the testis in the pig. Biol. Reprod. 2000, 63, 1629-1636. 